Article

\title{
Drawing Spirits in the Sand: Performative Storytelling in the Digital Age
}

\author{
David I. Tafler
}

Media and Communication, Muhlenberg College, Allentown, PA 18104-5586, USA; davidtafler@muhlenberg.edu

Received: 15 July 2019; Accepted: 12 August 2019; Published: 21 August 2019

\begin{abstract}
For First Nations people living in the central desert of Australia, the performance of oral storytelling drawing in the sand drives new agency in the cultural metamorphosis of communication practices accelerated by the proliferation of portable digital devices. Drawing on the ground sustains the proxemic and kinesthetic aspects of performative storytelling as a sign gesture system. When rendering this drawing supra-language, the people negotiate and ride the ontological divide symbolized by traditional elders in First Nations communities and digital engineers who program and code. In particular, storytelling's chronemic encounter offsets the estrangement of the recorded event and maintains every participants' ability to shape identity and navigate space-time relationships. Drawing storytelling demonstrates a concomitant capacity to mediate changes in tradition and spiritual systems. While the digital portals of the global arena remain open and luring, the force enabled by the chiasmic entwinement of speech, gesture and sand continues to map the frontier of First Nations identity formation and reformation.
\end{abstract}

Keywords: storytelling; sand drawing; Aboriginal media; performative speech; digital economy; oral culture

\section{Introduction: Spirit and System}

Telling stories really is a kind of power, and not an insignificant one. Stories give shape to experience, sometimes by accommodating traditional literary forms, sometimes by turning them upside down, sometimes by reorganizing them. Stories draw readers into their web, and engage them by putting them to work, body and soul, so that they can transform the black thread of writing into people, ideas, feelings, actions, cities, worlds, humanity, life. Storytelling, in other words, gives us the power to bring order to the chaos of the real under our own sign, and in this it isn't very far from political power.

THE BIG IDEAS: WHAT IS POWER?

“Elena Ferrante: A Power of Our Own," (Ferrante 2019)

In First Nations communities in remote areas in central Australia, performative practices such as oral storytelling accompanied by drawing in the sand navigate real experience within the virtual boundaries offset by the communication systems of cyberspace. Within those communities, first film and then satellite television opened channels to the outside world. Now, mobile and WIFI access allow the conglomerates of the social media world to entice and engage residents as they do elsewhere. On those digital devices, dreaming (texting, recording sound and images) becomes more ubiquitous but indiscernible from outside paradigms. Recollections from imaginary fabrications (music, movies, sports) compete with traces of memory from real world experience, an experience that encapsulates both celebratory and "sorry" (funereal) events.

In The Consequences of Modernity, (Giddens 1990) speaks of the disembodiment of social interaction from the participants' local temporal and spatial conditions as a distinguishing feature of modernity. 
"With the beginning of the modern era, he says, social space becomes increasingly independent of concrete places." Frequently, social interaction involves partners who do not inhabit the same geographical place and who communicate, often in real time, over great spatial distances. (Krueger 2004, p. 183) Imagine the consequences of living in such an expansive world when for a culture, a community, social interaction, not to mention individual identity, revolves around the immediate experience of presence in a particular geographical place.

In an outback world where less separation exists between the imaginary and the real, the normalization of the virtual community changes the nature of relationships. In those communities, initially formed as missions to protect people, to organize a more Western life style, and to formalize Western economic models, outsiders from a number of Christian religious organizations provided housing, resources, and routines meant to enhance life for previously semi-nomadic people. The community hubs formed from surrounding homelands inhabited by different families. Eventually, the Government granted First Nations people citizenship and assumed oversight of community operations. The people became dependent on government support.

With numbers of different families assembled from surrounding homelands, the remote communities have an illusory and fragmented unity aggravated by family allegiances exacerbated by the undefined boundaries and common territory of the community. While social problems continue to exist, innovations in communication and transportation have expanded the boundaries of the community. In remote areas such as the Anangu Pitjantjatjara Yankunytjatjara (APY) Lands along the northern border of South Australia, the new technologies help repopulate the scattered homelands and spread the nexus of community clusters. As the radius increases, the meaning of immediacy diminishes both among people, and between people and their surrounding environment. The spiritual imaginary encoded by the land, and the electronic imaginary coded by media experience change the experiential and spiritual cultural meaning of time and space.

The electronic and now digital world's mediation of spatial immediacy neutralizes the agency of presence, and the attendant signification of place (having special spiritual meaning) and event (having special temporal implication). Presence itself devolves into an ephemeral concept. Across time, the living and the dead cohabit the cultural world of photos, films, video clips. The living shadows and traces of deceased writers, directors, actors appear on the screen. Ancestors appear in databases. People find recorded evidence of their younger selves. New worlds of virtual reality (VR) go even further simulating the very presence of the living and/or the dead. In 1997 during an Ara Irititja (Aboriginal digital archive) demonstration on the APY Land, an older woman points out an unidentified infant in a photograph and self-identifies the child as herself many decades earlier. That recognition gets recorded as one more bit of information among the many details identifying people, places, and narratives in the photographs and films that comprise Ara Irititja's growing archive and database. As time goes on, the convergence between virtual and real time and place increases conceptually as a function of everyday experience and environment. Taboos against the viewing of the deceased begin to fade.

For many decades in many communities, Elders have recorded their Inmas (traditional dances) as well as other events. A national dedicated network ICTV (Indigenous Community Television) now broadcasts via satellite a daily stream of First Nations spiritual, sport, practical and personal stories compiled regularly from all over the country. Digital media expands this plethora of portals for recollection and broadens the opportunities for renewed and revitalized participation and engagement, measured in the number of hits attributed to an online presentation, and/or the number of online contacts compiled by a particular organization or individual. Multiple websites provide an array of music, dances, and spiritual stories for viewing in the public domain. Watching those events on a screen fortifies nostalgia. It resurrects and reshapes memories.

Though important for the preservation of identity, the empowerment of the digital stream does not substitute for individuals' presence and engagement in rituals and events, where participation provides agency and power that transcends observation. The digital community does not anchor 
ritualized behaviors, shared devotions and pieties. In the larger online environment, mythologies, values, goals, and moral doctrines shift and change as a process of interpretation subject to multiple perspectives, and histories.

Within the digital environment, vernacular storytelling sustains native language and reinforces local belief systems. On a spiritual plane, oral narration and its accompanying performative drawing foregrounds local knowledge and faith whose speculative assumptions contribute another perspective to global insight. Electronic tools expand the boundaries of storytelling experience, from drawing in the sand to posting in the cloud. On these virtual platforms, empirical knowledge from distant sources may broaden the base of storytelling references but it will lack that vital element of immediacy that accords the stories their essential meaning.

This article explores the enduring role of performative storytelling in preserving that essential meaning. Performative storytelling as practiced in remote central Australian First Nations communities by a narrator drawing in the sand during a story or conversation functions as an analog model that survives alongside proliferating digital tools and experience. Drawing stories in the sand re-embodies First Nations people in their relationship to nature, to their history, to technology and its culture. Its performative process remains an important corollary for not only navigating tradition and its spiritual dimension, but for negotiating the use of the evolving tools that help shape the larger environment. The rites of narrative in oral culture continue to evolve against the backdrop of electronic media's perpetual realignment. The ownership and protection of sacred stories and culture change in the transition from orality (memory) to recording (storage). Their accompanying though modified rituals, such a performative storytelling/drawing take on renewed cultural importance in a proliferating wider digital world. Fortifying the ephemerality of narrative's temporal construction, at critical stages in the genesis of the story or at its conclusion, the narrator using her hands or a storytelling stick (milpiri) will erase the rendered marks in the sand, clearing the slate for the next chapter, segment, or descriptive shot.

\section{Tradition and Storytelling}

For a long time in remote First Nations communities, the oral and gestural narration of stories have performed symbolic-cultural, spiritual-ritual acts supported by a community's extensive and largely shared conceptual framework of origin, ethics, and self-governance schemes (Lawson and McCauley 1990, pp. 19-20). Dating back thousands of years, the narratives evolved from the meanings inscribed by the movement of the ancestors across the myriad landscape of rises, dunes, waterholes, salt basins, notable trees, rock formations. The stories allude to ancestral agents wedded to features in the proximate landscape (the hills, rocks, dunes, and their surrounding flora and fauna) and stars (constellations) (Richerson and Christiansen 2013, p. 385). Traditional stories map the information encoded within territorial knowledge. Following the inscribed pathways inherited from the ancestors, Aboriginal Australians continued to navigate their way across their coded landscape for a very long time (Hirt 2012, p. 108).

Oral stories' long history of this temporal and spatial reference to country lingers in the encoded petroglyphs that date back thousands of years, in the more contemporary renderings on bark and canvas, on the ritual body drawings, and in the stories told by the elders of the community. Some of the stories and their representative codes remain privileged and protected across generations. Complex procedures guide access to those stories: who tells them, who hears them, and when to share the stories. The stories' eternal story time, place, space, and character communicate and pass on Aboriginal history, identity, knowledge, property, spirituality, and relationship boundaries (Stoller 2014, p. 472). Ownership and protection of the important stories insures social stability.

In a First Nations economy, story distribution follows strict rules. (1) The commerce of story ownership and protection assigns social, economic, and political value. The most important stories have currency as property, some sacred and proprietary, protected and privileged in their distribution. Certain members of the community own the stories; others have responsibility for their protection. (2) Oral storytelling sustains knowledge. (3) The stories transcend outside categorization schema. They 
combine inseparably elements defined on the outside as spiritual reflection, formal education, family bonding, commerce, and communication. (4) Time plays a significant role. Certain storytelling practices transpire in different ways at critical moments in the annual calendar. For example, during men's or women's "business," members of the community retreat to secluded areas for "storytelling rituals."

Storytelling commonality evokes community and reinforces ethical imperatives. Within communities, individuals collaborate to: (1) solve problems, (2) make collective decisions, (3) build relationships, (4) provide support, (5) share rituals and experiences, (6) establish identity and build status, (7) express ideas that construct meaning. (Constance Elise Porter. "Virtual communities and social networks" (Cantoni and Danowski 2015, p. 169) On a spiritual plane, five essential dimensions characterize storytelling activity: (1) belief, (2) practice (ritual and devotion), (3) experience, (4) knowledge, and (5) consequences (Glock 1962). They depend on shared standards of communication, education, identity formation, and individual-to-individual relations.

Stories map identity and social relations. At the Top End of Australia's Northern Territory Yolngu world, political and religious arrangements "must involve people from opposing moieties, and thus differing language groups." Moiety oppositions depend on the metaphors and embodiments that spring from mothers and their children (Yothu Yindi), each always assigned opposite moieties. The weaving together of these different identity categories shapes fundamental Yolngu agreement-making and spiritual practice (Christie 2005, p. 53). These Yolngu spiritual systems remain inseparable from social commerce. Tracking the changes transpiring in those arrangements illuminate the impact of cross-cultural influences.

As a performative component of the oral tradition, individuals in central desert First Nations communities will augment the narrative by drawing on the ground. A primary often sand surface, the ground maintains a link with the land, its rock, flora and fauna. Marking the ground, the narrator reinforces local collective memory. Augmenting the narrator's semiotic performance of signs and gestures in space,

the ground provides an additional surface for ephemeral codified graphic forms and an additional locus for enactment. This adds a dimension not usually considered in descriptions of the kinesic/visual modality. People point downwards to graphic schema, and use the ground for the anchoring of actions that begin on the ground and enact trajectories outward. (Green 2014, p. 237)

According to Walter Benjamin, rendered signs indicate intention, while marks simply appear (Benjamin 1996). In sand drawing, both signs and marks comingle in an elaborate discourse. The marks make the crucial difference for they appear as a consequence of the performance's spatial-temporal context, its location, the people present, the circumstances surrounding the narration.

\section{Digital Country}

Conceived and driven by outside imperatives, digital tools establish a different visceral connection with "country," no specific place, and maybe no time. The proliferation and functional logic of new mobile media: technological platforms, institutional arrangements, and representational strategies, expand transnational movements and restructure practices, discourses, patterns of adherence, and systems of exchange in virtually every region of the world today (Stolow 2013, p. 4). Digital materials, techniques, instruments, and expertise form a global grid of orientations, operations, and embedded and embodied knowledge and powers. Spiritual ideas, experiences, and actions remain both engaged and yet separate by their transcendent immediacy (or by an unmediated transcendent) (Stolow 2013, p. 5).

Discovering the presence of digital devices in a particular community or location reveals patterns of distribution, not origin. The devices have little or no connection with country. The rare metals within digital devices come from mining excavations around the planet. Laptops and smartphones in the community tip (waste dump) embody the imagination, design, workmanship, and materials characteristic of another country or of many countries. As tools lose their points of origin, as signs go 
global, the status of a particular location, not to mention the status assigned to a referential place loses meaning. When place becomes meaningless, space loses its spiritual significance. When spirituality loses its anchors, it becomes ephemeral memory, a locus of nostalgic identity, with meaning rooted in ancestry and not in living practices. Living practice in a secular world channels increasingly into a single market driven maelstrom of commerce.

Storytelling knows no boundaries. Storytelling embraces each new incarnation: new tools of production, new networks of distribution, and new genres. Story-making language and gesture systems co-exist with applications designed by engineers and programmers (Richerson and Christiansen 2013, p. 384; Christie 2005, p. 52). While media ontologies may mask the role of programmers and engineers, the users drive the market driven technology, both symbolically in their use of the tools and literally in the articulation of ideas and concrete configurations or artefacts in their everyday practice (Suchman 2002, p. 94). Spiritual practice and imagination negotiate media and its mediation-not just the textual or iconographic systems of media representation, but also the broader terrain of sensorial techniques, expressive tools, material formats.

In the i-Tjuma Project, Elizabeth Marrkilyi Ellis and Dr. Inge Kral, linguists and translators from the Centre of Excellence for the Dynamics of Language, and Dr. Jennifer Green from the University of Melbourne, examine how interaction with the modern world leads to changes in language. The project takes "the ancient, traditional practice of tjinytjatjunku tjuma ('to tell stories while drawing in the sand') and records younger storytellers' adaptations of this practice to iPads." Dr. Kral writes

We first experimented with a game app, but then it became obvious that i-Pads could replicate both the visual space and the action of drawing on a surface from the sand-story medium. The girls were able to adapt very readily from sand to screen. They were pulling up the menu, choosing colours, shapes and sizes in no time. And we've ended up with a collection of beautiful digital films and pictures. (Indigenous Storytelling Goes from Red Sands to iPads 2018)

The work with i-Pads helps to negotiate the boundaries between traditional and digital ways. It offers another avenue for adapting traditional culture to the lures and demands of the digital world. It does not, however, substitute for type of performative storytelling exemplified by drawing in the sand.

The medium plays a crucial role in the performance. Making marks on the ground plays a pivotal role in the concept of performance, which emphasizes the here and now. "Pulling up a menu, choosing colors, shapes and sizes" on an electronic tablet does not replicate the gestures, marks, and signs implanted on the ground. Drawing in the sand does not leave "a collection of beautiful digital films and pictures." That impermanence lies at the heart of the argument that performative drawing in the sand remains a crucial form of language that can inform digital practice but does not yet get fully appropriated by that practice. Their co-existence remains critical for maintaining the sense of place, time immediacy and the performative exercise that reaffirms identity in country.

Compelling parallels exist. In any culture, enabling very young children to develop their powers of self-expression proves most effective when children use paint on a large canvas, or sculpt their ideas with copious amounts of clay. The tactile use of these materials and the immediacy of movement, gesture, emotion, and realization of abstract ideas transcends pushing buttons and accessing menus programmed by engineers. Though messier, the older practices maintain a kinesthetic link with body-dance, the synthesis of thinking, emoting, responding. When using brush and pigment, and especially when using the free-flow kinesthetic capacity of one's hands, fewer outside forces intercede.

Contemporary stories that originate with younger people depart from older practices and do sit on open access global platforms. They enter the digital mainstream less protected and widely distributed. Beyond the community, no hierarchy of ownership and protection governs their transmission outside their local jurisdiction. Their storytelling loses its value as social currency. Meaning loses its linkage with country. The open border, random access, hyperlink topography of the Internet inoculates the privileged ownership of sacred information by specific individuals, families, or communities. While the 
protection paradigm guarantees the preservation and value of important mysteries, open access affords alternative paths that counter landscape's linear inscriptions of wisdom and education. Random and open access compromises the respect for elders who have acquired insights as part of a lifetime of lived experience. The multi-variant cultural randomness of the Internet departs from the linear tracks that shape the landscape into a contiguous text accessed by the process of taking a journey along one or more of those tracks. No wonder fundamentalist groups committed to specific spiritual practice(s) limit the exposure of their group members and children to outside influences.

As for the old stories, the mortality of the old storytellers coupled with the deficient traditional "education" and inattention of the younger generation, makes the imperative of finding other methods for saving knowledge from oblivion crucial to the preservation of culture. Dot painting on canvas offered a static archival option using signs and symbols analogous to those used when drawing in the sand. That did not resolve the challenge of securing a temporal option for encoding the unraveling of a narrative sequence in the genesis of an oral story. Recording the stories as an oral experience becomes an urgent priority, opening the possibility for unwelcome digital incursion. (Stoller 2014, p. 468) A troubled remedy, the digital documentation of protected stories impacts culture by contributing to changes in its social economy of ownership and protection, distribution and interpretation.

No longer fleeting, the stories become permanent, a film or video recording. The litany of performative gestures in storytelling, an analog experience, become susceptible to re-interpretation, re-configuration, and re-contextualization on a digital platform. In essence, the resonance of those gestures as gestures lose their relevance as traces of the narrator's particular history, life experience, cultural understanding.

Once a device records a gesture, inscription, map, or representation, the entire rendering process enters another dimension. Ancestral stories of spirits and ghosts morph online with many other narrative traditions and storytelling systems. Users can survey the respective discourses and assign their own legitimation values within their own socialization practices following their own religious commitments as well as ritual behavior in chatrooms, guest books, in FAQs, and in discussion forums and discussion lists on the Internet (Glock 1962). Emotions, beliefs, ethical standards, and performative repertoires accommodate and respond to "real world" technologies. Technology favors "the material appurtenances, mechanical operations, and expert knowledge that enable humans to act upon, and in concert with, the very tangible domains of nature and society. Spirituality frames the intangible realms of ritual expression, ethical reasoning, affect, and belief. The juxtaposition of both illuminates their "analogous binaries, including faith and reason, fantasy and reality, enchantment and disenchantment, magic and science, fabrication and fact." (Stolow 2013, p. 2).

In a world of recorded stories stored in the "cloud" (alongside photographs, films, and reams of information), community devolves in two ways: (1) The necessity of presence begins to dissipate; (2) The community's boundaries become ephemeral. As the boundaries defining the real-world change, rituals become representations of themselves. They lose the intensity and struggle of earlier times. In the past, time allowed land-based imperatives (distance, water food survival, family and tribe location) to drive the more prolonged periods needed for a young person's initiation and learning. Now, the initiates no longer have the stamina, the skills and motivation to venture far from home for extended periods of time. Engaging a larger world compromises the time needed for walking, a life-long process of local knowledge acquisition. Men's and women's business become increasingly emblematic, weeklong events and weekend walkabouts.

Community elders struggle to sustain the meaning of identity and to preserve that meaning across the cultural spectrum from everyday interaction to spiritual evocation. Stories engage a larger set of global signifiers, not connected to local visceral experience, history, identity, and meaning, tangibility or agency through the human body and human relations. Local events become more elusive when cut off from land formations, flora and fauna, family and friends. 


\subsection{Data and Metadata}

When the old stories move to digital databanks, the captured stories become increasingly vulnerable. (1) The new hierarchical environment vests a proportion of power with the digital engineers and coders. (2) No stasis exists in the digital world. Digital hardware and software evolve constantly. With the continual release of new tools, drives, updates and upgrades, digital archivists must remain vigilant to make sure the inscribed knowledge gets transferred when necessary. Each iteration opens up new potential portals, risking the compromise of story distribution procedures and the breech of sacred information. Access rules in the cloud can change.

In cyberspace, a digital "landscape's" coded inscriptions lie within categorical boundaries that sort out files and folders, assigning addresses to stored information. Cross referenced file designations do not correspond with the fluid nature and interwoven relations of captured stories. Moreover, navigating through those demarcations lacks the permanence of the rocks and the stars, of a rock and star based interface. Treading cyberspace, the non-linear walkabout lacks the fixed sequential inscriptions of a track or trek passed down through generations of experience, learning, tradition. Cyberspace lacks the geographical and cultural history that marks country, that marks the traditions that give people the capacity to belong to a place. Insofar as "country" means a locus of experience acquired by walking, living, looking around a particular set of memory inscribed places, country does not exist in cyberspace. Digital "country" becomes a kind of shorthand for the meanings tendered to the multiple spheres of human activity designated with arbitrary scripted borders (Kuhlke and Pine 2015, pp. 79-80).

Cyberspace spreads across many platforms and cloud systems. Topographical maps of cyberspace depict a matrix of dense clusters spreading to a plethora of outlying limb. Outstations, in turn, harbor their own recursions. The maps try to provide a holistic view of the myriad passages, networks, hyperlinks, dwarf sites; they try to find a legible formation, single static snap shots of an evolving grid (Dodge and Kitchin 2003, pp. 111-12). The digital terrain contrasts with the distinctions and contradictions of Aboriginal experience: "dispossession and belonging, resistance and consensus, destruction and preservation, center and border, past and future, space and place." Issues of history, context, diversity, and perspective complicate the experience of Australian country (Lambert 2010, p. 311).

\subsection{Mapping Territory}

Mapping this digital sphere introduces new symbolic gestures and references grounded within an online narrative landscape. As Jean Baudrillard suggested in Simulacra, the map precedes and engenders the territory or landscape. The system cuts loose the stories from their site of origin or reality. They become hypertext, packets of code, reconfigurable and potentially fragmented. The map supplants the real, whose vestiges only subsist here and there in the surrounding desert (Baudrillard and Foss 1983).

The advantages of heuristic efficiencies in metadata distribution co-exist with alternative ontologies. Whereas opaque database file and directory systems channel access to information through categorically referenced metadata programs, First Nations knowledge, structure and memory operate through layers of relatedness that transcend differentiating fields in the metadata structure (Christie 2005, p. 52). The stories realize their power through their performative experience (Suchman 2002, p. 94).

The map does not command the locus of attention. The drawing embodies the process of its own activity and that commands attention (Derrida 1990; van Alphen 2008). Oral narrative's performative structure retains its analog nuance. The analog creative drawing process sustains the philosophy, production and practice of Indigenous knowledge (Suchman 2002, p. 94). Performative storytelling maintains engagement and collaboration. Local "conversation" sustains systems of gesture and voice.

The practical balance between conceptual intrigue-the degree to which a work can afford viewers fresh mental insights on the theme or concept to which it alludes, and perceptual intrigue- - the degree to which the manipulation of the material qualities of the work might stimulate perceptual experiences causes the viewer to linger, and perceptual complacencies to be challenged. For Hegel, this lies 
halfway between intellectual understanding and sensual experience (Riley 2008). Cyber-events have their correlates in real world activity. In the virtual online world, users draw and map experiences in a fabricated environment formed of representations conjured from accessible photographs, films, physical artefacts, and written description. Performative orality navigates the territory between spiritual ephemera and physical experience. Performative story-drawing positions an analog interface alongside the electronic encounter.

\subsection{Speech Performance Writing}

Language's oscillation-who forms it, who speaks it, how a "writer" shapes it shifts over time between speech and writing/recording's inscribed formats. Each new technology has an impact starting with the invention of writing instruments and, of course, the printing press. Digital tools restage yet again the interplay between what Saussure labeled "langue et parole," speech and writing (de Saussure 1972). Most notably, ubiquitous handheld devices attached to global networks realign the local speech/inscription practices of their users. Digitally recorded and stored stories float in the global data stream, open to metadata cross referencing and recontextualization. That strains the preservation of local speech and its performative writing. In a digital world, the human performer enters a simulated reality governed by an outside body of rules, or "law." (Cantoni and Danowski 2015, p. 141).

Rousseau in his "Essay on the Origins of Language" (Rousseau 1998) posits the dystopian nature of the speech to writing/inscription convergency. It signaled the downfall of both language and fully human societies. Communities based on equity and sharing such as First Nations people, now face other forms of social inequality and hierarchy. Those with knowledge and the capacity to write (such as the agents of the Church) had greater power (Hendricks 2016). In First Nations culture, the owners and protectors of sacred stories have that power.

In contrast, speech evokes performance-the back and forth between the respective parties engaged in a conversation. Ann Cooper Albright writes that in dance the body performs an idea that hovers between "seeing and being seen; experiencing and being experienced." The movement itself serves as the representation of an idea in the process of formation (Albright 1997, p. 3). Dance embodies all performance. The performance functions as development, not as fact. Process outweighs product.

Spontaneity sustains agency in fortifying the meaning of performance. Performance maps out the exchange, a commerce predicated on an individual's presence and occupancy of a given space at that particular time. Merleau-Ponty hints at the essence of active engagement with language as an enveloping "field of action," intuitive and natural. The individual relates to language through its deployment.

I possess its articulatory and sonorous essence as one of the modulations or one of the possible uses of my body. I relate to the word just as my hand reaches for the place on my body being stung. The word has a certain place in my linguistic world, it is a part of my equipment. The only means I have of representing it to myself is by pronouncing it, just as the only means the artist has of representing to himself the work he is pursuing is by producing it. (Merleau-Ponty and Landes 2012, p. 186)

Once the performance has ended, the participants refer back to the moments of the experience, not to an existent text. Over time, memory opens up the experience to more interpretation.

In performance, storytellers maintain their spontaneity and agency. In the Primacy of Movement, Maxine Sheets-Johnstone writes about the essence of life reinforced by spontaneity. "Spontaneous movement is the constitutive source of agency, of subjecthood, of selfhood, the dynamic core of our sense of ourselves as agents, subjects, selves." (Sheets-Johnstone 2011, p. 119).

This original kinetic spontaneity that infuses our being and defines our aliveness, is our point of departure for living in the world and making sense of it. It is the epistemological foundation of our learning to move ourselves with respect to objects, and thus the foundation 
of a developing repertoire of "I cans" with respect to both the natural and artifactual array of objects that happen to surround us as individuals in our particular worlds. It is in effect the foundation of our sense of ourselves as agents within a surrounding world. (Sheets-Johnstone 2011, p.117)

\section{Electronic Watering Holes}

In 1998 while traveling across the Anangu Pitjantjatjara Yankunytjatjara lands in northern South Australia, an elder went out of his way to go off track to share and revisit significant sites frequented during his lifetime's cultural experience. Visiting the waterholes, hunting grounds, the old tracks that he wandered on foot and on horseback, the elder narrated how the walkabout shaped his maturation as a young adult, his acquisition of local knowledge, a communion with his ancestors, the realization of what eventually became a world perspective. Later, he lamented the fact that his own experience marked more or less the end of a generational cycle that lasted for thousands of years. When asked about his now grown children's own experience of "country," he acknowledged their lack claiming that television proved too great a distraction (Fraser 1998).

Television opens a readily accessible, everyday portal to a ubiquitous global narrative. Not only does the electronic interface illuminate the world beyond the distant hills, it conveys an alien and intoxicating value system predicated on commodities and their ownership. Television projects a more casual lifestyle and its attendant secular distractions. While television narratives depict conflict, the characters struggling in their survival face very different situational challenges.

Television's ephemeral tracks offer their own shared memories. Television, however, does not mark the beginning of cross-cultural commerce. The cultural interface of First Nations Australia's outside legacy starts with the mercantile trade between the coastal communities along the Top End and the Torres Straits with other South Pacific people. With the arrival of the First Fleet in 1788, contact brought disease, appropriation of land, missionary activity, ruthless aggression. Most recently, changes wrought by technology have set new precedents for cultural contagion, especially in the central desert areas. Toyotas reconstructed geography. Stores and bores made people less self-reliant. Monetary, food, and medical dependency spawned the formation of artificial communities that aggravated family feuds and fueled all of the problems inherent in congested living situations. The time demands for foraging bush tucker (native foods), waterholes, and natural medications diminished and disappeared. No suitable industry took their place. In their wake, ennui set in.

New transportation and communication tools displaced older, locally shaped movement and communication models predicated on a remote desert lifestyle. The new tools made the acquisition of capital a priority. That need shifted economic priorities and conditions to follow more finite conditional cause and effect practices, measured in material terms. On the one hand, the tools liberated individuals from the constraints of the central desert. On the other, the outside world imposed its own structured rules on behavior, relationships, economy and theology.

In this expanded economy, work activity required some coordination with the practices, and time constraints of the outside world. The new economy unsettled the temporal-spatial framework that privileged rites that fortified spiritual engagement. Moreover, outside systems assumed a hierarchical separation between spiritual rites and other forms of commerce. As travel expanded territory, and the outside economy constrained time, the new needs deflated the old values, a life-long, temporally layered pursuit of knowledge-learning the stories that anchor traditional practices.

Residents of remote communities relied increasingly on the commodities without necessarily assimilating easily the attendant commodified culture. Toyotas became an essential part of community transportation, with access a negotiated asset. An old fella in the film Black Heart (a portrait of cultural collision) makes this petition clear at the outset of the film. The transition from walking and animal transport to motorized vehicles on the land and in the air (and that includes drones) reconceive the temporal meaning of distance. Obviating the traditional walkabout rite of passage, the individual neophyte no longer walks the "loaded landscape," negotiating the sites of so many stories. 
When Ngangkaris (spiritual healers) astroplane around the planet, their hovering spirits mix with the jets overhead.

Replacing smoke and courier communication, the telegraph, the wireless, the telephone, broadcast media, and the Internet changed the nature of speech and its transmission. These series of inventions bridged the temporal gap between sending a signal and responding to it, foreshortening distance, and permitting instantaneous person-to-person encounters across a broad territory. (Stolow 2013) HF radio became hubs of social activity. Later, telephones-a one on one technology, replaced the HF "town hall" broadcasts. Telephone access lasted for short stretches. In a sharing culture, too many people used the service and exhausted the too little credit afforded the residents of a challenged economy. Within a short interval, the telephone company suspended service.

AUSSAT (the Australian Satellite) opened up the skies. Radio, and then television diminished local agency as the communication paradigm shifted from a one-to-many (HF) or one-to-one (telephone) active participatory exchange, to a one-to-many passive reception model. Lewis Mumford, American sociologist, warned that mass communication eroded the impact of local community on the fabrication of an individual's (let alone a group's) personality. As a force, technology had its own momentum hastened by the desire to overcome distance between family and friends, and between remote communities and the rest of the country, and the rest of the world. Technology, a creative force, produced a "third estate midway between nature and the humane arts." (Stolow 2013)

The digital environment added even greater access to a more friendly set of communication tools. With the diminution of their expense, media tools proliferated allowing larger numbers of people even greater access and control over their participatory interaction with a greater number of people around the world.

Global homogenization reshapes culture and orality. The confluence of information, misinformation, rumor, opinion, insight and knowledge from so many sources supplants the imagination and impacts the formation and preservation of identity. Global homogenization demands a steady stream of new stimulation. Those demands place new value on local traditions. They commodify spiritual culture, the traditional dances and renderings (Kuhlke and Pine 2015). Storage moves to the cloud.

Initiatives that tried to counter, for example the BRACS-Broadcasting in Remote Aboriginal Communities Scheme tried "fighting fire with fire" by enabling local communities to shoot and distribute (locally) their own cultural messages (from sports to spiritual activity), had only limited success. During the BRACS centralized narrowcasting period, communities could collectively decide to shift transmission to local content or to even shut down the broadcast environment for self-determined intervals (for example, for "sorry business"-a local funeral). That occurred rarely if at all. Across the broadcast/narrowcast spectrum, local content competed with national network programming. The lure of the outside world with its institutionalized glamour industries-movies and professional sports overwhelmed local content. While the elders, the tililpi (senior men) and minyma pampa (senior women), managed in some remote areas to exercise control over content, the exercise of that control diminished with the erosion of community interest.

Even that possibility passed. Beginning at the outset of the twenty-first century with a deadline of 2013, household digital dishes supplanted community analog receivers. Central narrowcasting of one set of signals to the whole community gave way to each household owning and controlling a satellite decoder. The decoder allowed each house the power to choose from among an ever-present array of multiple channels. The capacity for community oversight ceased to exist. Not surprisingly, while the Federal government supported the distribution and installation of household satellite dishes and decoders, their maintenance (which includes upgrades) became the burden of already challenged family households.

On this new satellite real estate alongside the multiple streams of highly produced commodified product from the Australian commercial and federally subsidized channels, a new national First Nations service emerged—ICTV (Indigenous Community Television). ICTV provides a rotating 24/7 
schedule of community-based production from around the continent to any decoder in the country on the VAST system. The first, and only, national indigenous community television service in the world has a complicated history with many struggles but it endures.

Unprecedented, ICTV gives communities control over how to frame their own stories. Amidst the cacophony in the global arena, ICTV provides the platform for the people to stage their own presence. It helps maintain identity, establishes a base for negotiating culture, helps network with other First Nations people. It affords children a sense of place and value. ICTV continues to evolve adjusting to the convergence of broadcast and Internet media.

As the broadcast paradigm shifts more and more to the Internet, many more channels with upload capacity promises even greater disruption. As WIFI networks and cellular coverage expand to remote communities, each individual has license, particularly the young, to program their own life experience in an array of unfiltered ways. In this social media world, the political and social implications of intrusion (bullying, peer pressure) jeopardize already challenged positions. More suicides occur. Communities based on a critical balance of interdependency, forged by the intimacy of small numbers, the boundaries set by family frontiers, and by spiritual codes that sustain longevity face the assault of individual independence coupled with global interdependence, both harbored beneath an umbrella of outside standards. That impacts in many ways, on thinking, on generational roles, on mobility, on education. The spiritual practices that endured for so long at the core of remote First Nations society move from center stage to a figurative role.

Outside paradigms of technology, commodity, economy, and politics supplant the construct of identity that lies along a long trajectory of land, territory, history. The spiritual traditions at the core of that identity formation become a point of futile resistance, no longer a system for thinking and living, more for harboring notions of ancestry, contextualizing a tribe's place in the world, an individual's relationship with his or her forebears, some lingering cement of commonality. Digital machines carry voices and messages through ethereal invisible channels to distant locations, with no connection to country and traditional culture. Carefully transmitted stories outside a protected regime lose their spiritual meaning on a global stage. They become infinitely incomplete according to the historical conditions of reception (Cantoni and Danowski 2015, p. 144).

Electronic databanks form emotionless cooperatives. The fictive kinship of many small-scale societies network people with different needs and expectations. (Cantoni and Danowski 2015, p. 142) Networks open portals across many fields, in a sense flattening them. Strings of text produce new presences (Christie 2005, p. 56).

Global disciplinary boundaries (theology, anthropology, sociology; economics, history, communication) have no succinct boundaries in non-western culture. No separation of scepter (state) and orb (church) materializes in Aboriginal society. First Nations spiritual culture in a global environment undergoes an awkward metamorphosis. Narrative structure in this ethereal world traverses a new topography. A web environment does not operate in the same manner as oral history, not to mention a book (the bible; the Koran; the Torah ... ; the Tibetan Book of the Dead ... ).

Within First Nations communities, land threads bind language and totems. Kinship relates to the networks of land totems, languages and ways of performing (Christie 2005, p. 53) Network threads build their own community. The land networks with their shared histories have lost their spatial grounding. In a series of waves or phases, they have become ephemeral, released from time, liberated from spatial tethers that protect meaning.

The heterogeneity of everyday experience does not translate to the tools. Even VR does not fully capture the experience of immersion. The goggles incapacitate sight at the same time that an individual enters the immersive environment. The goggles mask the immediate environment and supplant it with another. The artificial imaginary of VR places the individual outside lived experience, one step beyond tactile and kinesthetic engagement. On the horizon, robotics, bioengineering, and digitally mediated communications erode the boundaries between humans and their expanded bodies. New "cybergnostic" intelligence create a taxonomy of half-human, half-machine hybrids (Stolow 2013, p. 6). 
With this fabricated engagement, the individual loses the sense of time, the fragility of place, the essence of physical life.

\section{The Law: Ownership and Protection; Memory verses Storage}

In traditional Aboriginal culture, the "law" informs the sense of time, the fragility of place, the essence of life. The "law" refers to complex interweaving systems of canonized acceptable behavior transmitted through protected stories that ground specific social interactions. In First Nations communities, the law does not distinguish between spiritual mantras and everyday encounters. To the extent that the law operates through traditions that may or may not conform, to varying degrees, with the belief systems and practices of the surrounding cultures, outsiders mislabel the law, as "lore" or "dreamings," labels which reinforce arbitrary distinctions on how outside people understand the law's conception, structure, and operation. That ideologically driven separation has implications when understanding First Nations culture and when exploring the ramifications of digital experience on traditional culture.

"Jukurrpa," the law informs inform metonymic relationships among kin and metaphoric relationships with the land and its coded landscape. The law invokes a system of ethics and morality. The law invokes continuity. That continuity depends on the real-time social interactions and relations within the community. Community ceremonies work to preserve the law. The ceremonies retell, revisit the stories that constitute and inform the law. Insofar as the stories (the law) lie grounded in the landscape, the location of their retelling ceremonies has significance (Michaels 1987, pp. 28-34).

When the first fleet landed in 1788, the British did not recognize the law. Insofar as the First Nations people that they found appeared to have no "law," the settlers decreed the land "terra nullius" (unoccupied by any inhabitants with whom they had to negotiate). That ill motivated misguided edict provided the legal and quasi moral foundation for over two hundred years of land theft and mistreatment of First Nations people.

Ironically, in the new digital arena, notions of terra nullius have become an issue for prospective and active voyagers in cyberspace. As cyberspace evolves, many corporate players contest access rights and rules of ownership. In a concomitant struggle, smaller organizations and unaffiliated individuals try to maintain their own footprint access rights. In remote communities, the new (digital) media environment bears similar ramifications. Cyberspace distends the law. First Nations people's struggle with the challenge of bringing new media "into the law" contends with what media anthropologist Eric Michaels describes as "an unprecedented stream of alien fiction" in a culture which does not distinguish fiction, or authorship (Michaels 1987, pp. 28-34). New stories move across the online border beyond the narrative umbrella that constitutes the law. That sets up new challenges for absorbing new narrative into the law, as tributaries branching out from the original story lines. Conversely, two tiers of narrative formation emerge, a system that more closely resembles the manifold hierarchies of outside cultures, that separate important texts like the Bible or the Koran from pulp fiction.

When celebrating, reciting and reinforcing the law, the temporality of the performative ritual shifts value from the physical icon in the environmental to the performative gesture, from the manifest object, icon, or text to the shifting metamorphosis of individual and collective memory. Memory remains an active and mutable component of the exchange system. Unlike storage (which has some permanence), memory undergoes perpetual flux. Collective memory has the capacity to shift gradually from generation to generation, to adjust its groundings and nuances from group to group. Each enduring body of knowledge remains subject to the individual's or group's emotional and intellectual constitution. Each retained gesture or event can alter the pattern in a story's transmission. While the law endures from generation to generation, it has the capacity for mutability, for coming into the present as warranted by traditional practice and local custom.

In contrast, Inge Kral points out that technology immortalizes the present. Young people roam the community recording daily events and shaping community memory. Posting those events on social media inscribes a fixed record of those events. The collective memory has ramifications, for example 
when a recorded flight fuels lingering resentment. When digital databases form a communal reservoir of information and stories, memory loses its malleability and potential for more limitless signification (Kral 2012).

Unlike storage, the limitations of memory (or the individuals' capacity to forget) allows for the "refreshing" of that experience. Metaphorically, it resembles the electronic dance that refreshes the pixels on the digital screen, but not exactly in the same way. The individual can have gray areas of recollection whereas in a digital world, the switch lies in either the on or off position. Some trace of code might continue to exist, though when retrieved it proves indecipherable. In a pseudo form of aphasia, the individual can project any manner of world where thought and objective language combine in some fundamental activity (Merleau-Ponty and Landes 2012, pp. 196-97).

At the locus of memory, the cloud, ethereal sites comprised of networked databanks in unknown locations, establish a destination without a spatial location. The cloud harbors stories embedded in algorithms shaped by programmers. The encoded stories lie in files and folders allocated for retrieval by people who meet certain conditions. The ceremonial relations that govern the transmission of stories on the ground yield to the programmed codes and passwords of cyberspace.

Digital technology governs access in a more limited and narrow way than the circumstances (selection of time and place) inherent in human communication. Heidigger talks about the singularity of the dammed river that precludes the multiplicity of forces in its channel (Heidegger 1999). In the same way, the digital world reduces all operations (design, cinematography, calculation) to a single platform. Outside engineers control the codes. People may study the stories in advance of sharing ceremonies, but that stage of deliberation changes the nature of culture.

A digital scrapbook in the cloud has a different nuance than a physical storehouse. On the ground, the local community controls access and distribution of compiled images and artifacts. In the cloud, corporate systems with their marketing priorities shape the imperatives. Their orientation, approach, sequencing, and summarizing operations contrast with local, in particular Aboriginal culture.

With all of the discussion of data breeching, the environment has a volatile nature that does not assure the ancestral protections and tribal traditions that have governed the discourse, the transmission of stories in the past. The gatekeepers control the codes, and they can override them. In fact, the engineers and code keepers determine the new forms of becoming, and not the individuals whom they serve allegedly.

\section{Proprietary Knowledge verses Open Access Enlightenment}

The dissemination of protected knowledge in a larger world of open-access changes incrementally a world where knowledge equals property; where the custodial obligations of preserving knowledge include policing its distribution; in a world where knowledge equals capital. Governing the encounters means controlling the intersections; that implies some say in the control of structure. Gateways and portals acquire meaning from a legacy of storytelling, where the storytellers pass on proprietary knowledge selectively.

Every phase of recording, storing, and transmitting stories has hastened the transformation of story preservation and transmission, dating back to the printing press. Every technological innovation, from film to video, from analog to digital adds another layer of profound change. The evolution of the text impacts the structure of the story, its incremental format, its transmission and retransmission, the reception by the enveloping culture, the law.

As storytelling transmission changes, from picture books to chapter books; from oral to written expression; from living to recorded experience, the act of story transmission loses its fluid capacity to shift and change with the circumstances encompassing the telling. They include: the relationship between the storyteller and receiver, the relationship between the time and place of the story's origin and the temporal-spatial site of its exposition, the circumstances governing the telling of the story, for example whether its motivation(s) and justification derives from spiritual, group, family or other special interest bodies. When the stories rely upon literacy or digital literacy, the storytelling process 
evolves beyond the codes compiled over time in speech, or gesture. In short, the inscribed stories coded accessibility might allow for broader distribution and exposure in a world that stretches the locus of shared experience, then mythologizes it, and, finally, places it online.

In this simulated world, people know the world through the images recorded. People see their world through a mobile phone lens, and give it meaning through networked memories on social media. Each reference assembles a hub of orbiting references, which in turn form their own referencing systems. Subjects move in time trying to guarantee their own permanence (Merleau-Ponty and Landes 2012, p. 71). By the time individuals visit a real site, a locus of information in the real world, transmitted data in the virtual world has already formed their background impressions. The virtual impression frames the real experience, one way or the other.

\section{Performative Storytelling in the Sand}

Much more fragile than storage, memory depends upon living transmission, in the real world. Though the transmission tools have evolved to include new forms of auditory and visual communication, the custodian of a story must still build a provisional frame around that story for it to survive intact, fully loaded with at least a trace of its spiritual significance and overtones of meaning. In an oral exchange, transmission relies on both the storyteller and story recipient sharing a contiguous spectrum of spatial-temporal interaction and historical understanding. Most notably in First Nations communities, the individuals must share some commonality of history and understanding tied to country in order to engage the symbolic codes that inscribe the pertinent (hi)story. Both parties need not reside in the same place, though they do need to exist at the same point in time to preserve orality.

Performative speech, gesture, drawing preserve traditional systems for protecting, owning, and transmitting the stories, the repository of memories. Ritualized storytelling, dance, song recycle memory at ceremonial moments. Informal moments of day-to-day storytelling often around a campfire, mimic and reinforce traditional oral and performative storytelling practice.

Notwithstanding the electronic environment, individuals reaffirm their agency of the lived experience. Storytelling validates continuously the commingling of everyday experience and cosmic sacred models. Narrating stories by drawing in the sand, First Nations women sustain and recreate the ancestors' systems of communication and meaning. They reaffirm the law, the proximity between life's daily patterns and the transcendent values encoded by the sacred stories. (Dubinskas and Traweek 1984)

Local traditions shape early storytelling behavior. Stories and storytelling's systematized encounters begin at the earliest stage of a child's development. An essential part of a young individual's identity formation, social positioning, capacity to make sense of an incomprehensible universe, storytelling's succinct, linear episodes give meaning to both every day and extraordinary events.

As a small child, the young individual engages with narrative, simultaneously as co-producer, as an agent in the transmission, as subject. The young child takes "up an imaginary position within the natural world of [narrated] significations." This pre-objective transaction shapes the child's sense of agency in directing his or her experience of the larger world (Merleau-Ponty and Landes 2012, p. 280). As the child matures, as the teller and listener begin to comprehend their own experience in the context of natural and human history, storytelling's multiple layers including its embedded metaphoric symbolism, convey more complex meaning.

The subject takes up a position in the world of his significations through gesture, an accompaniment to speech. Gesture bridges the interior realm of "thought" with the external and surrounding world. That "mental" or "cultural" life "borrows its structures from natural life," grounding the thinking subject with the embodied subject. For the speaking subject and for those who listen, "the phonetic gesture produces a certain structuring of experience, a certain modulation of existence" just as the body invests the environment surrounding the speaker and others with a certain signification (Merleau-Ponty and Landes 2012, p. 199).

Speech and gesture evolve over a lifetime. Beginning with oral a parent's oral narration, soon accompanied by (picture book) illustrations, the small child conjures the different spatial temporal 
environments described in the communicated narrative. Association and empathy begin to develop in correlation with specific characters. As part of the transmission process, the storyteller and the child point to the illustration, identify story elements, make analogical references to the surrounding social and physical environment.

In this ontogenesis of speech and gesture, some "studies of very young children have suggested that pointing, followed by symbolic gestures, preceded the acquisition of speech." (Kendon 2017). Regardless, the pointing process engages the child, allows the child some agency in directing attention to the characters, objects, surrounding features that capture attention and contain those certain meanings that adhere to the community's social structures. Merleau-Ponty emphasizes the value of gesture as a reification of the body, integrating the body as a vehicle for understanding and sketching out the structure of the world. The value of the gesture lies in how it mobilizes the viewers' gaze as part of the fabrication of meaning. The story serves as the vehicle in this integrative performance (Merleau-Ponty and Landes 2012, pp. 191-92).

Arguments go back and forth regarding the relative origin and proportional value of gesture in its relationship with speech (Corballis 2002). Linguists have addressed speech as a multi-modal communication practice that includes signs and gestures. Some, like Adam Kendon, a noted scholar on gesture, have explored the equivalence of speech and gesture "utterances." Carla Cristilli in her essay "Digital lives in post-colonial Aboriginal Australia" argues that vocal and bodily actions constitute two different semiotic systems. According to Cristilli, speech harbors a "more abstract and analytical conceptualization of the referent than gesture." Gesture relies more on iconic meaning expressed simultaneously with speech. In other words, gesture lacks a complex grammatical system (Cristilli 2014).

As a gesturing system, drawing in the sand defies inscription, permanence, interpretation. It functions as a kinesic extension of orality, an integrated composite of speech, sign, schema drawn on the ground (Green 2014). Some might argue that through the marks etched in the sand, drawing makes material the abstractions conjured in speech. Therefore, it harkens back to the earliest stages of narrative experience with its focus on illustration as a form of pre-literacy, making tangible the objects posited by the text. Merleau-Ponty posits a more complex semiotics of speech and illustration. When the individual reads the drawn signs or marks, they only exist as representations tied to some identifiable grain of knowledge. In that identification, the participant re-emerges as a player in the exchange (Merleau-Ponty and Landes 2012, p. 74). Residual memory evokes the local encoded signs, the everyday commerce of performative communication.

Two women sit on the ground. "Women achieve the most elaborated forms of this dynamic storytelling practice." (Green 2014). They talk, gesture, and simultaneously make marks in the sand with either their hands or with sticks. The images in the sand evolve, change, and disappear. As the narration progresses, lines, shapes, and their combined signs appear and then get erased and replaced by another set of marks, "an elaborate graphic system for communication." A system built upon a set of designs called guruwari-circles, lines, curves and several other 'simple' graphic forms, people use their hands to work the designs into the sand as they talk. The thick line drawings parallel those that appear on the bodies of ritual dancers, and represent the gestures reproduced in the choreographies of sacred dance-dramas as well as in the dramatisation of dreams (Dubinskas and Traweek 1984). The spoken word takes shape, moves through the air, and dissipates. The accompanying sand inscription features gestures, momentary illustrations that have a short half-life. The next set of marks capture the notes, chords, and overtones of the narration. As two tropes in the same discourse, the oral narrative and the rendered drawings harmonize in their respective roles as part of the discourse performance.

Sand stories begin with the clearing of a space on the ground in front of a seated narrator, or, in situations where several narrators engage in collaborative storytelling, by adjacent spaces. 'Sand', with its variety of desert colours and textures is the medium of inscription and in part it is this ecological niche - the ready availability of such surfaces—that defines the geographic range and the social context of the practice. The ephemeral graphic schema and mini-installations of leaves and other small objects that populate this space provide anchors for the unfolding discourse and 'targets' for acts of signing 
and pointing (Haviland 1993, 2000, 2003). Deictic gestures and sign/pointing composites function as narrative 'tracking' devices, mediating speech to sand. As each scene in the story ends the space is wiped clear before the drawing begins again. At times the spatial location of graphic elements that previously existed - the palimpsest—is used as the deictic field to anchor actions that are part of the on-going story. Various speech styles, including the creative use of intonation and the adaptation of ordinary speech to song-like rhythm and meter add to the complexity (Green 2014).

Through the drawing process, the storyteller's body performs the story. Occasionally, the narrator may use both hands to sign and draw. The narrator's body serves "as a locus for the articulation of certain signs (kin signs or signs that indicate body parts) and for embodied representations of story actions." Body posture correlates with the narrative context (Green 2014). Through gestures, the narrator performs an analog dance with the ground and with other individuals.

In sand stories, narrators deftly oscillate between metanarrative commentary and 'in-character' enactments when they take on the role of characters in the story. Deictic gestures focus attention on graphic representations of referents drawn on the ground, and various verbal strategies, including the creative use of prosody and of sentential particles such as the direct speech marker "kwenh," signal shifts in perspective and mark actual or imaginary speech. These represent small speech performances, with storytellers "playing the part" of a story character (Green 2014). Attendant individuals (including the designated recipient of the story) can participate and will sometimes alter the marks in the sand in response to some aspect of the narration. Those adjustments may represent corrections, adjustments, comments, or insights.

Drawing in the sand's multidimensional, complex coordination with spoken narration transpires in real time and space. Conversation participants interpret, adapt, and appropriate a set of signs and gestures attached to complex systems of positioning tied to that time and space. In physical space, the performative exchange between two or more people subsumes the local within the broader context. Moreover, it foregrounds the relationship between the respective parties. As Merleau-Ponty points out, the individual does not communicate with "representations" or with a thought, but rather with a speaking subject, with a certain style of being, and with a targeted "world." (Merleau-Ponty and Landes 2012, p. 189). In sand stories,

a mix of intrinsic or scene-internal frames of reference and extrinsic ones place narratives within the context of regional and ancestral topographies in absolute space. Intrinsic frames of reference refer to scene-internal or simple binary relationships between figure and ground based on inherent properties of either-for example canonical orientations of objects which have a 'front' and a 'back'. In sand drawing this smaller space corresponds to the drawing space in front of the narrator where graphic schema and the small objects used as story props are close at hand and "visually available" to interlocutors. (Levinson and Wilkins 2006, p. 567; Green 2014)

Performative drawing resembles ideational drawing. Rosenberg defines ideational drawing as "thinking space" with an emphasis on process and not on the eventual artifact-the drawing. He makes clear that ideational drawing does not mean a rendering that re-presents thought. The focus lies on the immediacy of the drawing as a "thinking-act." Whereas "thought" implies a concluded, settled, and in some way objectified act, ideational drawing remains an "ongoing creation, a continuing emergence of thinking meaning (Rosenberg 2008).

The process of drawing evokes an idea, that transcends its marks. The performance of retelling a story contributes additional nuances. The gestures, marks in the sand, comments, deconstructions get made and remade with each narration in the minds of the participants (Kuhlke and Pine 2015, p. 81). Merleau-Ponty writes: "Once the performance has come to an end, we cannot do anything in our intellectual analyses of the music but refer back to the moment of the experience." (Merleau-Ponty and Landes 2012, p. 188). 
The moment-to-moment performance draws upon a semiotically rich environment of speech and a lexicon of sign languages amalgamated from gestures and drawing composites. Sand story techniques can migrate to other surfaces-the ground, dashboards of moving vehicles, the surface of the skin, and floors and carpets in buildings in more casual acts of inscription. (Kral 2012; Green 2014, p. 237).

Heidegger wrote that one must learn to think. An important part of this thinking process, the hand plays an important part that contrasts with its more benign role pushing buttons on digital tools. (thinking = handicraft). The hand is something altogether peculiar. In the common view, the hand is part of our bodily organism. But the hand's essence can never be determined, or explained, by its being an organ that can grasp. Apes, too, have organs that can grasp, but they do not have hands. The hand is infinitely different from all grasping organs-paws, claws and fangs-sdifferent by an abyss of essence. Only a being who can speak, that is, think, can have hands and can handily achieve works of handicraft (Heidegger 1999).

The hand transcends grasping, catching, pushing and pulling. The hand forms an instrument of communication, connection, gesture, design and signs (Rosenberg 2008). In the use of smartphones, the hand seems to outweigh the eyes when it comes to shooting moving footage. Too often, individuals capture moving images on their smartphones in a portrait (vertical) mode in opposition to the landscape (horizontal) mode of sight. The linear design and format of smartphone negates perception and demonstrates the lack of cinematic understanding.

\section{Memory and Cinematic Erasure}

While cinematic understanding does not inform performative drawing, corollaries exist. As it appears and then disappears, each temporal layer of coded marks in the sand contributes to the changing ephemeral passage of the narrative. Each new rendered phase of the drawing contributes another metonymic stage in an evolving text loaded with material references and symbolic meaning. As the total narrative unravels in time, the fleeting drawings (first drawn and then erased) take shape as a coherent pattern in a string of memory, in short, a film. The drawings disappear but their fragments, signs and gestures endure in the recollected moments tied to the story.

In "Signs and space in Arandic sand narratives," linguist Jennifer Green describes sand drawing's temporal process, the appearance and disappearance of images that compile in memory, the tropes inherent in cinematic structure.

The data are segmented into ... visual frames, delimited by full erasure of the story space (Green 2014). Erasure is a ready-made episodic marker and one of the signature affordances of the sand story medium. Likened to the drawing of a curtain on a stage set, erasure correlates with changes in time/space and is thus a useful indicator of the narrative structure of the stories (Munn 1973, pp. 69-72; Wilkins 1997; Green 2014). Erasure is also used to micro-manage scene-internal changes in sand stories. It enables sequences of visible narrative action to be superimposed on top of one another in the same spatial plane, and changes in scene are thus directly and visibly evoked as the sand screen is periodically 'refreshed'. For the time that a particular visual frame persists the narrator may sporadically cease drawing on the ground and use sign or gesture, and then orient themselves to the ground space in front of them and continue drawing. (Green 2014, p. 226)

In cinematic structure, each successive shot erases the preceding in a continual play of new shots and scene transitions. Each movement from one shot to the next implies the movement or passages of time. Though recorded as a photographic image, a trace of light on a segment of film, or as a series of zeros and ones in an algorithmic file, each cinematic frame ( 24 frames per second in film; and either 25 or 30 frames per second in video, depending on the technological standard in that part of the world) appears and disappears as a fleeting impression, usually compiled as part of a shot. In turn, the shots appear and disappear sequentially one after the other either abruptly in a cut, or gradually 
as part of a fade or dissolve. Each shot plays out with the preceding and following shots as part of an overall metonymic (linear) structure over the duration of a film. The cinema's structural resemblance to everyday visual perception enables the audience to decipher the spectacle on the screen with little difficulty. The set of cinematic storytelling conventions acquired through years of film/television viewing and usage complete the process of accessibility.

Cinema did not invent erasure. Before cinema, the act of erasure constituted an important part of the drawing process, often read in the adjustments made by the artist. In portraiture, the marks and lines on the canvas evoke the subject of the portrait's presence at that particular moment. The subject moves, the artist corrects, and the drawing evolves demonstrating that relationship. Perception in time guides the movement of 16th century Dürer's hand. Each line in his contemporary Holbein's drawn portraits has an analogous connection to the subject. Dürer allows all his lines (even the "mistakes") "to breathe life into his self-portrait. In more contemporary artist Armando's drawings, the drawn lines trace an activity instead of an intentional object or concept meant as a product for the representation." The viewer sees "the activity itself, not the activity's object or goal." The work of art "forces itself, as object, upon the viewer." (van Alphen 2008).

Unlike attending the cinema or viewing a rendered drawing, the interlocutors share a common space with the narrator, actor, renderer during the time of a story-performance event. Merleau-Ponty's emphasizes how the interactive presence of both participants-the performer and interlocutor underpin the range of subtle kinesic and overt gestures that the performer may render. The body serves as a proxemic sign purveyor of intention insofar as the performer responds to the audience present. The audience responds in kind to the intent of the performer. When describing this interaction, Merleau-Ponty highlights the reciprocity between one person's intentions and the other person's gestures, and between the gestures and the intentions read in the other person's behavior. Each identifies with the other, "as if the other person's intention inhabited [one's] body," and vice versa. Gestures indicate intentional "specific sensible points in the world." (Merleau-Ponty and Landes 2012, pp. 190-91).

While the body occupies and navigates a particular space within a given time, the subject can use his or her imagination to transport virtually anywhere through the rendered narrative. The narrative can cross all sorts of multi-dimensional boundaries, across time (future and past) and space. Separate from the subject and yet connected, the narrative maps a narrator's movement through the dance of spatial relations (the landscape), temporal events (the stories), community (relations among individuals), and cyberspace (the virtual body; Kuhlke and Pine 2015, pp. 79-82).

The performative kinesthetic process "defines an emergent, ever expanding consciousness whose structures unfold on the ground in spontaneous movement. Through the performer's interpretation, qualitative spatio-temporal concepts emanate from the marks in the sand (Sheets-Johnstone 2011, p. 119).

\section{Conclusions: The Story, a Never Ending Becoming}

The drawing at the locus of sophisticated and poetic human interaction animates the flow, patterns, and shapes of movement in a format that appears locked in time and inanimate. It directs attention to the chiasmic flow of memory, the imagination, and reason. Fortifying thought, performative story-drawing uses a spatial and gestural system of embedded concepts and embodied perception (Kozel 2008).

Each story has a latent capacity for modification and reinvention with each incarnation nuanced by the narrator's time, place, and relationship to the narrative. When the storyteller retells the story, his or her own inner landscape re-makes the stories into multi-centered and reflexive new narratives. In the retelling, multiple voices compile over time, over generations. The story remains in a never-ending process of becoming, contingent on how circumstances reframe the narration over time. As places change, as the environment embraces other influences, as the storytelling traditions share the "stage" 
with other new media for storytelling experience, notably the never-ending cyclical news and sports, the stories change (Kuhlke and Pine 2015, pp. 92-93).

Storytelling's performative rendering has no direct digital equivalent. The emphasis lies in the performative moment, the capacity for change, nuance, and response to the fluid circumstances engulfing a particular rendition. Shooting an image of a selfie that tells the story of a particular moment in an individual's life, or passage to a particular space experience at that moment in time fixes the transcription. At the moment witnessed and recorded the performance ends. Even if the image lacks permanence through the built-in algorithms of temporality built into a particular social media application, it loses the flexibility of alteration (alterative reformation) after the fact. Granted, different parties can doctor the image at any time, but that opens other avenues of inquiry and examination.

The Anthropocene notes a time when modern culture simultaneously realizes its capacity for destruction and re-invents its own myth of creation. The frontier represents that tension-laden, interactive historic moment of encounter where civilization will overcome its immediate obstacles. In contrast, the frontier poses a key site for the reflexive critique of contemporary society (Rose 2005). That critique resists the specific meanings read from precise locations within country as identified and remembered in the stories or scriptures of certain groups and collectives (de Vries 2008). The loss of slippage seems endemic to a technological world.

So called exotic digital technologies mark epochal cultural shifts in contrast to mundane technologies, which have lost their novelty and now linger in the background outside the discursive glare. Yet, mundane technologies such as drawing constitute the "normal, the ordinary, the invisible" against which digital technologies perform and have meaning. Meanwhile, in the interstices of everyday habitual communication where drawing sustains normality, little performative/semiotic abnormalities encompass small disruptions and subversions that can lead to greater cultural changes (Michael 2000).

In the digital age, First Nations people model activities that can resonate across cultures. Drawing can function as a universal instrument to connect with country in an ephemeral electronic digital age. While First Nations people recognize the importance of country, country plays an important part in the fabrication of identity everywhere, recognized or not. In the vast expanse of the universe, humanity's relationship to the planet, its water, rocks, flora and fauna cuts across all disciplines and grounds all areas of inquiry. Humanity lives off the planet; its ashes return to the soil.

Too often spiritual activities search the heavens for solace, enlightenment, as a destination that vanquishes the fear of mortality. The concept of the "cloud" expands those ethereal planes. The singularity offers a promise that the mind can transcend the limitations of the body and endure indefinitely. Drawing in the sand does not arrest those speculations and desires. It does provide another foundation for not forgetting the essence of existence. More so than ever in an age of climate change, that essence needs redirection back to Earth.

Drawing endures as a common communicative modality of phenomenological reflection. Drawing gives voice to the narrator's experience in a performative arena where others understand the tools of expression and process the modalities of reflection-the marriage of perception and imagination, to generate thinking and meaning. The lived experience of the narrator informs the conceptual paradigms (Kozel 2008).

Russian Formalist theorist Viktor Shklovsky spoke about art as a vehicle for strengthening perception. He described art as a process of thinking "in images" that resists the habitual day-to-day automatic behavior that dulls the senses. Therefore, art must defamiliarize the unconscious complex lives led by most people.

Art exists that one may recover the sensation of life; it exists to make one feel things, to make the stone stony. The purpose of art is to impart the sensation of things as they are perceived and not as they are known. The technique of art is to make objects "unfamiliar," to make forms difficult, to increase the difficulty and length of perception because the process of perception is an aesthetic end in itself and must be prolonged. (Shklovsky 2015) 
As ICTV makes available to the community user the instruments of a digital age, drawing mediates and provides structures and codes for interaction. Drawing reinforces the body in a creative enterprise, in the continuing genesis of language, in the exploration of presence, in the computation of time. Drawing enhances the individual's capacity to see. The individual renders the patterns of events and actions as well as those of the surrounding world, whether fabricated in their own cognition or existent in nature.

Drawing re-embodies humans in their relationship to nature, technology, and culture. The human body, sometimes in its corporeality and agency described as discrete and unitary, has inherent interconnectedness with the environment, the tools, and traditions. All of those contribute in complex ways to each other's constitution (Michael 2000).

Drawing allows the narrator to adapt and modify reflective processes, to play with them and improvise through them to permit openings that allow for the emergence of the seemingly illogical, intangible, ambiguity of belief systems, of the law. In their impermanence, the marks in the sand indicate the dynamic ontological state of entwinement or entanglement between the law and identity, tradition and change, a constant sliding state of exchange. Drawing performs the meeting point of pre-reflective and reflective, pre-rational and rational thought (Kozel 2008). Performative drawing in the sand remains an indelible part of the new environment and its ongoing catharsis of insight and mystery, ignorance and enlightenment, secular technology and spiritual transcendence. From the marriage of perception and imagination, thinking and doing, the narrator's motion transforms time and space and marks the boundaries of subject and object, identity and difference, presence and absence, sound and silence, self and other, in the sand (Kozel 2008).

Funding: This research received no external funding.

Conflicts of Interest: The author declares no conflict of interest.

\section{References}

Albright, Ann Cooper. 1997. Choreographing Difference: The Body and Identity in Contemporary Dance. Middleton: Wesleyan University Press.

Baudrillard, Jean, and Paul Foss. 1983. Simulations. New York: Semiotext(e), Inc.

Benjamin, Walter. 1996. Paintings, or Signs and Marks. In Selected Writings, Volume 1, 1913-1926. Cambridge: Harvard University Press, pp. 83-86.

Cantoni, Lorenzo, and James A. Danowski, eds. 2015. Communication and Technology. Berlin: Walter de Gruyter $\mathrm{GmbH} \& \mathrm{Co} \mathrm{KG}$.

Christie, Michael. 2005. Words, Ontologies and Aboriginal Databases. Media International Australia Incorporating Culture and Policy 116: 52-63. [CrossRef]

Corballis, Michael C. 2002. From Hand to Mouth: The Origins of Language. Princeton: Princeton University Press.

Cristilli, Carla. 2014. How gestures help children to track reference in narrative. In From Gesture in Conversation to Visible Action as Utterance: Essays in Honor of Adam Kendon. Edited by Mandana Seyfeddinipur. Amsterdam: John Benjamins Publishing Company.

de Vries, Hent. 2008. Introduction: Why Still “Religion”? In Religion: Beyond a Concept. Edited by Hent de Vries. New York: Fordham University Press, pp. 1-98.

Derrida, Jacques. 1990. Mémoires d'aveugle: L'autoportrait et Autres Ruines. Paris: Éditions de la Réunion des Musées Nationaux. (In French)

Dodge, Martin, and Rob Kitchin. 2003. Mapping Cyberspace. London: Routledge.

Dubinskas, Frank A., and Sharon Traweek. 1984. Closer to the Ground: A Reinterpretation of Walbiri Iconography. Man 19: 15-30. [CrossRef]

Ferrante, Elena. 2019. Elena Ferrante: A Power of Our Own. The New York Times. May 17. Available online: https://www.nytimes.com/2019/05/17/opinion/elena-ferrante-on-women-power.html (accessed on 5 June 2019).

Fraser, Donald. 1998. conversations with David I. Tafler, on the Anangu Pitjantjatjara Yankunytjatjara Lands. July 22. 
Giddens, Anthony. 1990. The Consequences of Modernity. Cambridge: Polity Press.

Glock, Charles Y. 1962. On the study of religious commitment. Religious Education 57: 98-110.

Green, Jennifer. 2014. Signs and space in Arandic sand narratives. In From Gesture in Conversation to Visible Action as Utterance: Essays in Honor of Adam Kendon. Edited by Mandana Seyfeddinipur. Amsterdam: John Benjamins Publishing Company.

Haviland, John B. 1993. Anchoring, iconicity and orientation in Guugu Yimithirr pointing gestures. Journal of Linguistic Anthropology 3: 3-45. [CrossRef]

Haviland, John B. 2000. Pointing, gesture spaces, and mental maps. In Languages and Gesture: Window into Thought and Action. Edited by David McNeill. Cambridge: Cambridge University Press, pp. 13-46.

Haviland, John B. 2003. How to point in Zinacantan. In Pointing: Where language, Culture, and Cognition Meet. Edited by Sotaro Kita. Mahwah: Erlbaum, pp. 139-69.

Heidegger, Martin. 1999. What Calls for Thinking. In Basic Writings. Edited by David Farrell Krell. London: Routledge, pp. 369-91.

Hendricks, Gavin P. 2016. Deconstruction the end of writing: "Everything is a text, there is nothing outside context". Verbum et Ecclesia 37: 1-9. [CrossRef]

Hirt, Irène. 2012. Mapping Dreams/Dreaming Maps: Bridging Indigenous and Western Geographical Knowledge. Cartographica: The International Journal for Geographic Information and Geovisualization 47: 105-20. [CrossRef]

Indigenous Storytelling Goes from Red Sands to iPads. 2018. Available online: https://www.anu.edu.au/news/allnews/indigenous-storytelling-goes-from-red-sands-to-ipads (accessed on 11 July 2019).

Kendon, Adam. 2017. Reflections on the "gesture-first" hypothesis of language origins. Psychonomic Bulletin and Review 24: 163-70. [CrossRef] [PubMed]

Kozel, Susan. 2008. Closer: Performance, Technologies, Phenomenology. Cambridge: MIT Press.

Kral, Inge. 2012. Talk, Text and Technology: Literacy and Social Practice in a Remote Indigenous Community. Bristol: Multilingual Matters.

Krueger, Oliver. 2004. The Internet as Distributor and Mirror of Religious and Ritual Knowledge. Asian Journal of Social Science 32: 183-97. [CrossRef]

Kuhlke, Olaf, and Adam M. Pine. 2015. Global Movements: Dance, Place, and Hybridity. Lanham: Lexington Books.

Lambert, Anthony. 2010. (Re)Producing Country: Mapping Multiple Australian Spaces. Space and Culture 13: 304-14. [CrossRef]

Lawson, E. Thomas, and Robert N. McCauley. 1990. Rethinking Religion: Connecting Cognition and Cutlure. Cambridge: Cambridge University Press.

Levinson, Stephen C., and Daniel P. Wilkins, eds. 2006. Grammars of Space, Explorations in Cognitive Diversity. Cambridge: Cambridge University Press.

Merleau-Ponty, Maurice, and Donald A. Landes. 2012. Phenomenology of Perception. London: Routledge.

Michael, Mike. 2000. Reconnecting Culture, Technology and Nature: From Society to Heterogeneity. Milton Park: Taylor \& Francis.

Michaels, Eric. 1987. For A Cultural Future: Francis Jupurrurla Makes TV At Yuendumu. Melbourne: Artspace.

Munn, Nancy. 1973. Walbiri Iconography. Graphic Representation and Cultural Symbolism in a Central Australian Society. Ithaca and London: Cornell University Press.

Richerson, Peter J., and Morten H. Christiansen. 2013. Cultural Evolution: Society, Technology, Language, and Religion. Cambridge: MIT Press.

Riley, Howard. 2008. Drawing: Towards an Intelligence of Seeing. In Writing on Drawing: Essays on drawing Practice and Research. Edited by Steve Garner. Bristol: Intellect Books.

Rose, Deborah Bird. 2005. The redemptive frontier: A long road to nowhere. In Dislocating the Frontier. Edited by Deborah Bird Rose and Richard Davis. Canberra: ANU Press, pp. 49-66.

Rosenberg, Terry E. 2008. New Beginnings and Monstrous Births: Notes Towards an Appreciation of Ideational Drawing. In Writing on Drawing: Essays on Drawing Practice and Research. Edited by Steve Garner. Bristol: Intellect Books.

Rousseau, Jean-Jacques. 1998. Essay on the Origin of Languages and Writings Related to Music. Hanover: Dartmouth College Press.

de Saussure, Ferdinand. 1972. Course in General Linguistics. Chicago: Open Court Publishing Company.

Sheets-Johnstone, Maxine. 2011. The Primacy of Movement. Amsterdam: John Benjamins Publishing Company. 
Shklovsky, Viktor. 2015. Art, as Device. Poetics Today: International Journal for Theory and Analysis of Literature and Communication 36: 151-74. [CrossRef]

Stoller, Paul. 2014. Commentary: Storytelling and the Construction of Reality. Literature and Medicine 32: 466-73. [CrossRef] [PubMed]

Stolow, Jeremy. 2013. Introduction: Religion, Technology, and the Things in Between. In Deus in Machina: Religion, Technology, and the Things in Between. New York: Fordham University.

Suchman, Lucy. 2002. Located Accountabilities in Technology Production. Scandinavian Journal of Information Systems 14: 91-105.

van Alphen, Ernst. 2008. Looking at Drawing: Theoretical Distinctions and their Usefulness. In Writing on Drawing: Essays on Drawing Practice and Research. Edited by Steve Garner. Bristol: Intellect Books.

Wilkins, David P. 1997. Alternative representations of space: Arrernte narratives in sand. In Proceeding of the CLS Opening Academic Year '97/98. Edited by Monique Biemans and Joost van de Weijer. Nijmegen: Nijmegen/Tilburg Center for Language Studies, pp. 133-64.

(C) 2019 by the author. Licensee MDPI, Basel, Switzerland. This article is an open access article distributed under the terms and conditions of the Creative Commons Attribution (CC BY) license (http://creativecommons.org/licenses/by/4.0/). 